\title{
Prognostic value of myocardial fibrosis in patients with severe aortic valve stenosis
}

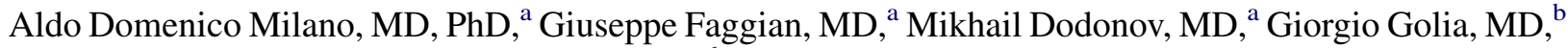 \\ Anna Tomezzoli, MD ${ }^{\mathrm{c}}$ Uberto Bortolotti, MD, ${ }^{\mathrm{d}}$ and Alessandro Mazzucco, $\mathrm{MD}^{\mathrm{a}}$
}

\begin{abstract}
Objective: To evaluate whether myocardial fibrosis influences left ventricular performance in severe aortic stenosis and to assess its effect on long-term survival after aortic valve replacement.
\end{abstract}

\begin{abstract}
Methods: Myocardial fibrosis was evaluated in biopsy specimens taken from the interventricular septum in 99 patients undergoing aortic valve replacement because of severe or prevalent aortic stenosis. Clinical and echocardiographic evaluations were performed at a mean follow-up of $6.2 \pm 3.0$ years. The patients were classified according to the myocardial fibrosis severity (none or mild in 28 , moderate in 52, and severe in 19).
\end{abstract}

Results: Patients with severe myocardial fibrosis had a dilated left ventricle and positive association between the left ventricular end-diastolic diameter $(\mathrm{R}=0.77, P<.001)$, left ventricular end-systolic diameter $(\mathrm{R}=0.78$, $P<.001)$, left ventricular end-systolic wall stress $(\mathrm{R}=0.74, P<.001)$ and the degree of myocardial fibrosis. Myocardial fibrosis was inversely related to left ventricular fractional shortening $(\mathrm{R}=-0.64, P<.001)$, left ventricular ejection fraction $(\mathrm{R}=-0.53, P<.001)$, and left ventricular relative wall thickness $(\mathrm{R}=-0.70, P<.001)$. Patients with a higher grade of myocardial fibrosis had a significantly lower freedom from cardiac death at 10 years $(42 \% \pm 19 \%$ vs $89 \% \pm 6 \%, P=.002)$, with congestive heart failure the most common cause of death. At Cox regression analysis, patient age $(P=.012)$, low preoperative transvalvular gradient less than $40 \mathrm{~mm} \mathrm{Hg}$ $(P=.040)$, preoperative end-systolic wall stress $(P=.046)$, and preoperative myocardial fibrosis grade $(P=.034)$ emerged as the strongest independent predictors of mortality.

Conclusions: In patients with severe aortic valve stenosis, the amount of myocardial fibrosis appears to have significant effect on clinical status and long-term survival after aortic valve replacement. From these results, we believe that new strategies for the earlier detection of myocardial fibrosis are needed to achieve a better prognostic outcome. (J Thorac Cardiovasc Surg 2012;144:830-7)

Left ventricular (LV) hypertrophy produced by pressure overload in aortic stenosis (AS) is an adaptation that compensates for high intracavitary pressures with the goal of normalizing wall stress and maintaining adequate cardiac output. ${ }^{1,2}$ However, recent studies have questioned the beneficial role of LV hypertrophy in AS, suggesting that an increased LV mass might be a predictor of ventricular dysfunction. ${ }^{3,4}$ Persistently elevated systolic wall stress and compromised myocardial perfusion lead to myocyte degeneration and myocardial fibrosis (MF), with a significant relationship between the degree of such morphologic alterations and LV function. ${ }^{5,6}$ In the presence of $\mathrm{MF}$, the increased $\mathrm{LV}$ mass might not be

\footnotetext{
From the Divisions of Cardiac Surgery, ${ }^{\mathrm{a}}$ Cardiology, ${ }^{\mathrm{b}}$ and Department of Pathology, University of Verona, Verona, Italy; and Division of Cardiac Surgery, ${ }^{\mathrm{d}}$ University of Pisa, Pisa, Italy.

Supported by Cariverona Project 2008, Verona, Italy.

Disclosures: Authors have nothing to disclose with regard to commercial support.

Received for publication Sept 8, 2011; revisions received Oct 17, 2011; accepted for publication Nov 9, 2011; available ahead of print Jan 13, 2012.

Address for reprints: Aldo Domenico Milano, MD, PhD, Division of Cardiac Surgery, University of Verona, Piazzale Stefani 1, Verona 37126 Italy (E-mail: aldo. milano@univr.it).

0022-5223/\$36.00

Copyright (c) 2012 by The American Association for Thoracic Surgery doi:10.1016/j.jtcvs.2011.11.024
}

effective in normalizing wall stress and maintaining LV function. ${ }^{7}$ The decrease in cardiac output might result in lower than expected transvalvular gradients, with either a preserved or decreased LV ejection fraction (LVEF). ${ }^{8}$ This underestimation of AS leads to a late indication for aortic valve replacement (AVR) with a negative effect on the prognosis. Recent studies have proved that MF could be an important morphologic substrate affecting the early and late results after AVR, especially in patients with severe AS and a low transvavular gradient. ${ }^{9-11}$

The aim of the present study was to assess the effect of MF degree, determined at histologic examination of endocardial biopsy specimens, on LV function and its prognostic value on mortality in patients requiring AVR for severe AS.

\section{METHODS}

All patients gave informed consent to undergo myocardial biopsy performed intraoperatively during AVR and for such specimens to be used for experimental purposes. Afterward, the local institutional ethics committee approved the clinical and instrumental evaluation for the present study.

\section{Patient Population}

From January 1999 to December 2006 at Verona University Hospital, 99 patients underwent concomitant isolated AVR and multiple biopsies of the interventricular septum to study the preoperative morphologic 


\begin{tabular}{|c|c|}
\hline \multicolumn{2}{|c|}{ Abbreviations and Acronyms } \\
\hline AS & $=$ aortic stenosis \\
\hline AVR & $=$ aortic valve replacement \\
\hline ESWS & $=$ end-systolic wall stress \\
\hline FI & $=$ fibrosis index \\
\hline FTMI & $=$ fibrous tissue mass index \\
\hline $\mathrm{HR}$ & $=$ hazard ratio \\
\hline LV & $=$ left ventricular \\
\hline LVEDD & $=\mathrm{LV}$ end-diastolic diameter \\
\hline LVEF & $=\mathrm{LV}$ ejection fraction \\
\hline LVESD & $=\mathrm{LV}$ end-systolic diameter \\
\hline LVFS & $=\mathrm{LV}$ fractional shortening \\
\hline LVPWT & $=\mathrm{LV}$ diastolic posterior wall thickness \\
\hline LVPWTs & $=\mathrm{LV}$ systolic posterior wall thickness \\
\hline MF & $=$ myocardial fibrosis \\
\hline MTMI & $=$ myocyte tissue mass index \\
\hline NYHA & $=$ New York Heart Association \\
\hline
\end{tabular}

abnormalities of the LV myocardium. During the same period, 1362 patients underwent ad AVR at our institution. The patients with significant coronary artery disease, previous cardiac surgery, and a history of myocardial infarction and excessive asymmetric basal septal hypertrophy were excluded. The limited number of patients included in the present study represents the experience of a single surgeon (G.F.). The mean patient age was $71 \pm 10$ years, with 64 patients $(65 \%)$ older than 70 years. Of the 99 patients, $43(43 \%)$ were men and $56(56 \%)$ were women. All patients had pure or prevalent AS caused by calcified valve degeneration. The mean New York Heart Association (NYHA) functional class was 2.6 $\pm 0.7 ; 8$ patients $(8 \%)$ were in class I, $33(33 \%)$ in class II, $52(52 \%)$ in class III, and $6(6 \%)$ in class IV. The preoperative clinical and hemodynamic data are summarized in Table 1. As a part of the preoperative assessment, all patients underwent selective coronary angiography. A recording of the intracardiac pressures and transvalvular gradients was possible in 79 patients $(80 \%)$.

\section{Echocardiographic Evaluation}

Standard M-mode and 2-dimensional echocardiographic measurements were collected according to the American Society of Echocardiography criteria. ${ }^{12}$ All Doppler measurements were averaged for 3 cycles in patients with sinus rhythm or for 5 cycles in those with atrial fibrillation. The subaortic peak and mean velocities, mean pressure gradient, and velocity-time integral were measured from the pulsed-wave Doppler recordings in the 5-chamber apical view, with the sample volume placed just below the point of fast flow acceleration. The severity of AS was assessed by measuring the aortic valve area and peak and mean transvalvular gradients calculated using a standard formula based on the principle of continuity of flow. The LV end-diastolic diameter (LVEDD), LV end-systolic diameter (LVESD), diastolic and systolic septal wall thickness, and diastolic and systolic inferior wall thickness (LVPWTd and LVPWTs) were measured using M-mode echocardiography. LV fractional shortening (LVFS) was calculated as follows: $100 \times($ LVEDD-LVESD)/LVEDD. The ejection fraction was calculated according to Simpson's rule: ejection fraction $=$ (end-diastolic volume - end-systolic volume)/end-diastolic volume. The LV mass was calculated according to the Devereux formula ${ }^{13}$ and indexed for body surface area (LV mass index). The relative wall thickness (RWT) was calculated according to the formula: RWT $=(2 \times$ LVPWTd $) / \mathrm{LV}$ end-diastolic internal dimension. The LV end-systolic wall stress (ESWS) was calculated as follows: ESWS $=0.334 \times \mathrm{P} \times$ LVESD/[LVPWTs $\times(1+$ LVPWTs/ LVESD)], where $\mathrm{P}$ is the left ventricular peak systolic pressure calculated as the sum of systolic blood pressure taken by sphygmomanometry plus the peak aortic gradient evaluated by Doppler. ${ }^{14}$ Patients with ESWS greater than $120 \mathrm{kdyne} / \mathrm{cm}^{2}$ were considered to have inadequate cardiac hypertrophy, calculated as the mean \pm standard deviation of ESWS values obtained by Serneri and colleagues ${ }^{7}$ for the same pathologic finding.

\section{Surgical Data}

All patients underwent surgery under moderate hypothermic cardiopulmonary bypass with topical cooling and infusion of anterograde and/or retrograde cold blood cardioplegia. After aortic crossclamping through a transverse aortotomy, the aortic valve leaflets were excised, and careful decalcification of the aortic annulus was performed, if necessary. Prostheses were implanted using multiple interrupted stitches buttressed by subannular Teflon felts. The following prostheses were implanted: Hancock porcine (Medtronic, Minneapolis, MN) in 44 patients (45\%); Edwards Perimount pericardial (either standard or Magna models; Edwards Lifesciences, Irvine, CA) in $26(26 \%)$; Sorin Bicarbon bileaflet (Sorin Biomedica, Saluggia, Italy) in $15(15 \%)$; Carbomedics bileaflet (Sorin Biomedica) in $10(10 \%)$; and Sorin Freedom pericardial stentless (Sorin Biomedica) in $4(4 \%)$. The prosthetic size was $21 \mathrm{~mm}$ in 25 patients $(25 \%), 23 \mathrm{~mm}$ in 55 $(56 \%), 25 \mathrm{~mm}$ in $17(17 \%)$, and $27 \mathrm{~mm}$ in $2(2 \%)$. A total of 16 patients underwent concomitant procedures, including mitral valve surgery in 12 $(12 \%)$ and ascending aorta replacement in $4(4 \%)$. A total of 10 patients underwent concomitant limited myectomy.

\section{Endomyocardial Biopsy and Patient Groups}

After removal of the aortic valve, 3 samples of myocardial tissue were taken using a standard bioptome from the basal LV septum. All samples were stored overnight in $10 \%$ formaldehyde solution, embedded in paraffin, cut in 2- $\mu \mathrm{m}$-thick sections, and stained with hematoxylin-eosin and Masson's trichrome stain. The relative volume of myocardial muscle and fibrous tissue was determined by point counting using a $10 \times 10$ grid at a total magnification of $100 \times{ }^{15,16}$ A hypertrophied myocyte (defined as a cell diameter $>15 \mu \mathrm{m}$ ) tissue index (myocyte tissue mass index [MTMI]) was calculated as a percentage by dividing the sum of the hypertrophic areas of the section by the sume of the total tissue area. It was graded as mild $(<20 \%)$, moderate $(20-50 \%)$, and severe $(>50 \%)$. The MTMI was expressed as the percentage of hypertrophied myocytes $\times$ LV mass index/100 $\left(\mathrm{g} / \mathrm{m}^{2}\right) .{ }^{15}$ The fibrosis index $(\mathrm{FI})$ was calculated by dividing the sum of the fibrotic areas of the section by that of the total tissue area and expressed as a percentage, as described by Tanaka and collegues. ${ }^{17} \mathrm{Ac}-$ cording to the FI, the patients were classified as having no or mild fibrosis (FI $<20 \%$; group 1), moderate fibrosis (FI, 20-50\%; group 2), or severe fibrosis (FI $>50 \%$; group 3; Figure 1). The fibrous tissue mass index $\left(\right.$ FTMI) was estimated as FI $\times$ LV mass index $/ 100\left(\mathrm{~g} / \mathrm{m}^{2}\right){ }^{18}$

Although FI is a valuable parameter to assess the extent of pathologic changes in the myocardium, we also used the FTMI for better correlation with the LV mass value, as suggested by Lund and associates. ${ }^{19}$

\section{Data Collection and Follow-up}

All clinical and pathologic data obtained from the database of our institution were entered into designed study forms. Next, the clinical and echocardiographic data were prospectively collected at 6 and 12 months and yearly thereafter. The last follow-up information for hospital survivors was obtained during a 6-month interval ending in June 2010. Unsuccessful attempts to trace patients were followed by contact with the family members or the referring physicians. Considered as an end point, the last followup information, efforts were made to assess the cause of late deaths. The cause of late mortality was defined complying with recently revised guidelines. ${ }^{20}$ In particular, cardiac death was defined as any documented death related to a cardiac event, such as myocardial infarction or progressive cardiac failure or any sudden, unexplained death. 
TABLE 1. Baseline characteristics

\begin{tabular}{|c|c|c|c|c|c|}
\hline \multirow[b]{2}{*}{ Characteristic } & \multirow[b]{2}{*}{ All $(\mathbf{n}=99)$} & \multicolumn{3}{|c|}{ MF grade } & \multirow[b]{2}{*}{$P$ value } \\
\hline & & $1(n=28)$ & $2(n=52)$ & $3(n=19)$ & \\
\hline Mean age (y) & $71 \pm 10$ & $70 \pm 9$ & $72 \pm 9$ & $72 \pm 13$ & .757 \\
\hline Gender & & & & & .833 \\
\hline Male & 43 & 11 & 24 & 8 & \\
\hline Female & 56 & 17 & 28 & 11 & \\
\hline $\mathrm{AF}$ & $13(13)$ & $4(14)$ & $6(12)$ & $3(16)$ & .875 \\
\hline Diabetes & $20(20)$ & $8(29)$ & $8(15)$ & $4(21)$ & .373 \\
\hline Arterial hypertension & $37(37)$ & $9(32)$ & $17(33)$ & $11(58)$ & .121 \\
\hline PVD & $16(16)$ & $9(32)$ & $4(8)$ & $3(16)$ & .018 \\
\hline Angina & $36(36)$ & $10(36)$ & $19(37)$ & $7(37)$ & .923 \\
\hline Syncope & $15(15)$ & $5(18)$ & $7(15)$ & $3(16)$ & .844 \\
\hline Mean NYHA & $2.6 \pm 0.7$ & $2.4 \pm 0.7$ & $2.5 \pm 0.7$ & $3.1 \pm 0.6$ & .001 \\
\hline LVEDD (mm) & $54 \pm 7$ & $47 \pm 6$ & $54 \pm 5$ & $64 \pm 5$ & $<.001$ \\
\hline LVESD (mm) & $37 \pm 8$ & $29 \pm 6$ & $37 \pm 5$ & $47 \pm 5$ & $<.001$ \\
\hline LVPWTd (mm) & $12 \pm 2$ & $14 \pm 1$ & $12 \pm 2$ & $10 \pm 2$ & $<.001$ \\
\hline LVPWTs (mm) & $16 \pm 3$ & $17 \pm 2$ & $16 \pm 2$ & $13 \pm 2$ & $<.001$ \\
\hline LVSWTd (mm) & $14 \pm 2$ & $16 \pm 1$ & $14 \pm 2$ & $11 \pm 1$ & $<.001$ \\
\hline LVSWTs (mm) & $18 \pm 3$ & $20 \pm 2$ & $18 \pm 2$ & $14 \pm 2$ & $<.001$ \\
\hline LVFS (\%) & $33 \pm 8$ & $39 \pm 6$ & $33 \pm 6$ & $24 \pm 5$ & $<.001$ \\
\hline RWT & $0.47 \pm 0.13$ & $0.61 \pm 0.10$ & $0.44 \pm 0.07$ & $0.31 \pm 0.04$ & $<.001$ \\
\hline LVEF (\%) & $53 \pm 9$ & $57 \pm 7$ & $55 \pm 8$ & $42 \pm 7$ & $<.001$ \\
\hline LVEF < $<50 \%$ & $29(29)$ & $3(11)$ & $12(23)$ & $14(74)$ & $<.001$ \\
\hline $\operatorname{LVMI}\left(\mathrm{g} / \mathrm{m}^{2}\right)$ & $194 \pm 32$ & $196 \pm 33$ & $194 \pm 30$ & $190 \pm 38$ & .837 \\
\hline ESWS (kdyne/cm²) & $115 \pm 56$ & $65 \pm 20$ & $109 \pm 29$ & $206 \pm 41$ & $<.001$ \\
\hline RVSP (mm Hg) & $38 \pm 11$ & $37 \pm 7$ & $37 \pm 11$ & $44 \pm 17$ & .232 \\
\hline RVDP (mm Hg) & $3.6 \pm 2.2$ & $3.6 \pm 1.9$ & $3.5 \pm 2.4$ & $3.8 \pm 2.4$ & .966 \\
\hline PASP (mm Hg) & $36 \pm 12$ & $35 \pm 9$ & $35 \pm 11$ & $43 \pm 19$ & .207 \\
\hline PADP (mm Hg) & $14 \pm 7$ & $14 \pm 6$ & $14 \pm 6$ & $18 \pm 10$ & .229 \\
\hline MWP (mm Hg) & $15 \pm 8$ & $14 \pm 7$ & $14 \pm 7$ & $19 \pm 12$ & .192 \\
\hline Aortic PG (mm Hg) & $78 \pm 18$ & $78 \pm 18$ & $79 \pm 18$ & $74 \pm 19$ & .599 \\
\hline Aortic MG (mm Hg) & $49 \pm 13$ & $50 \pm 11$ & $51 \pm 14$ & $44 \pm 12$ & .175 \\
\hline Aortic $\mathrm{MG}<40 \mathrm{~mm} \mathrm{Hg}$ & $23(23)$ & $4(14)$ & $10(19)$ & $9(47)$ & .018 \\
\hline Aortic VAi $\left(\mathrm{cm}^{2} / \mathrm{m}^{2}\right)$ & $0.39 \pm 0.10$ & $0.39 \pm 0.08$ & $0.39 \pm 0.09$ & $0.40 \pm 0.10$ & .789 \\
\hline FTMI $\left(\mathrm{g} / \mathrm{m}^{2}\right)$ & $61 \pm 32$ & $24 \pm 9$ & $65 \pm 17$ & $104 \pm 20$ & $<.001$ \\
\hline MTMI $\left(\mathrm{g} / \mathrm{m}^{2}\right)$ & $79 \pm 34$ & $75 \pm 45$ & $82 \pm 30$ & $77 \pm 21$ & .002 \\
\hline
\end{tabular}

Data presented as mean \pm standard deviation or numbers, with percentages in parentheses. $M F$, Myocardial fibrosis; $A F$, atrial fibrillation; $P V D$, peripheral vascular disease; NYHA, New York Heart Association functional class; $L V E D D$, left ventricular end diastolic diameter; $L V E S D$, left ventricular end-systolic diameter; $L V P W T d$, left ventricular diastolic posterior wall thickness; $L V P W T$, left ventricular systolic posterior wall thickness; $L V S W T d$, left ventricular diastolic septal thickness; $L V S W T s$, left ventricular systolic septal thickness; $L V F S$, left ventricular fractional shortening; $R W T$, relative wall thickness; $L V E F$, left ventricular ejection fraction; $L V M I$, left ventricular mass index; $E S W S$, end systolic wall stress; $R V S P$, right ventricular systolic pressure; $R V D P$, right ventricular diastolic pressure; $P A S P$, pulmonary artery systolic pressure; $P A D P$, pulmonary artery diastolic pressure; $M W P$, mean wedge pressure; $P G$, peak gradient; $M G$, mean gradient; $V A i$, indexed valve area; $F T M I$, fibrosis tissue mass index; $M T M I$, myocyte tissue mass index.

\section{Statistical Analysis}

The data are presented as the mean \pm standard deviation for continuous variables and as simple percentage for categorical variables. A comparison of the mean values was performed with the paired and unpaired $t$ test or analysis of variance method in the case of more than 2 groups in the analysis. The percentages were compared using the chisquare or Wilcoxon tests, as appropriate. Linear regression analyses were used to assess the correlation between MF and LV function. Overall survival and freedom from cardiac death were determined using Kaplan-Meier actuarial analysis and are expressed as the percentage of patients who were event free \pm standard error. Cox regression analysis was used to examine the effects of the predictors of cardiac death. Statistical analyses were performed using SPSS, version 16.0.1 (SPSS, Chicago, Ill).

\section{RESULTS}

\section{Endomyocardial Biopsies}

According to the myocardial morphology of the septal biopsy specimens, the patients were divided into 3 groups (Table 1). Group 1 (no or mild MF) included 28 patients $(28 \%)$ with a mean FTMI of $21 \pm 8 \mathrm{~g} / \mathrm{m}^{2}$ and a mean MTMI of $65 \pm 39 \mathrm{~g} / \mathrm{m}^{2}$. Group 2 (moderate MF) included 52 patients $(53 \%)$ with mean FTMI of $66 \pm 20 \mathrm{~g} / \mathrm{m}^{2}$ and a mean MTMI of $83 \pm 33 \mathrm{~g} / \mathrm{m}^{2}$. Group 3 (severe MF) included 19 patients $(19 \%)$ with a mean FTMI of $130 \pm 29 \mathrm{~g} / \mathrm{m}^{2}$ and a mean MTMI of $96 \pm$ $28 \mathrm{~g} / \mathrm{m}^{2}$. 


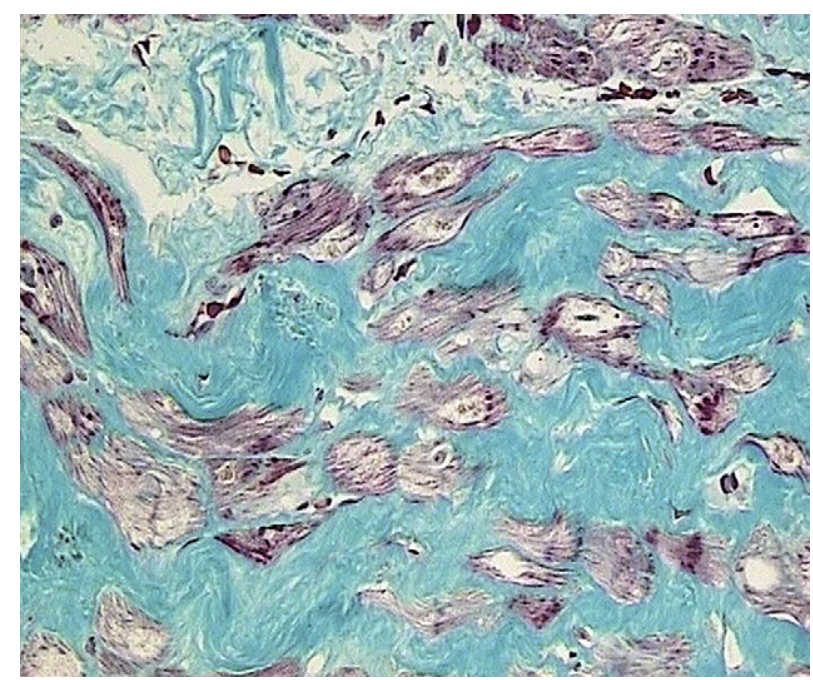

FIGURE 1. Sample of myocardium stained with Masson's tricrome $(25 \times)$ showing severe fibrous tissue between myocardial cells.

\section{Preoperative Cardiac Function and Myocardial Morphology}

The baseline patient characteristics are listed in Table 1. The NYHA functional class was significantly better in groups 1 and 2 than in group 3. In the entire population, the patients with impaired LV function had a greater mean wedge pulmonary pressure and right ventricular systolic pressure. Patients with severe fibrosis showed signs of cardiomiopathy with myocardial dysfunction (LVEF, 42\% $\pm 7 \%$ ), dilated LV (LVEDD, $64 \pm 5 \mathrm{~mm}$; LVESD, $47 \pm 5 \mathrm{~mm}$ ) and reduced LV wall thickness (RWT, $0.31 \pm 0.06$ ). Thus, a positive association was found between the LVEDD ( $\mathrm{R}=0.77, P<.001)$, LVESD $(\mathrm{R}=0.78, P<.001)$, and ESWS $(\mathrm{R}=0.74, P<.001)$ and the degree of FTMI (Figure 2). In contrast, MF was inversely related to LVFS $(\mathrm{R}=-0.64, P<.001)$, LVEF $(\mathrm{R}=-0.53, P<.001)$ and RWT $(\mathrm{R}=-0.70, P<.001$; Figure 3). Severe AS with a low transvalvular gradient was found in 23 patients $(23 \%)$, regardless of the LVEF, but most of the patients with a low transvalvular gradient and low LVEF were found in the group with the greatest degree of MF ( $47 \%$ and $74 \%$ of the group, respectively).

Adequate LV hypertrophy was found in 63 patients (mean ESWS, $81 \pm 22 \mathrm{kdyne} / \mathrm{cm}^{2}$ ), and 36 had an inadequate cardiac hypertrophy (mean ESWS, $176 \pm 47 \mathrm{kdyne} /$ $\mathrm{cm}^{2}$ ). In patients with adequate hypertrophy, the increase in LV mass was mainly related to the increase in the LV wall thickness (LVPWTs, $18 \pm 2 \mathrm{~mm}$ vs $14 \pm 2 \mathrm{~mm}$, $P<.001)$. However, in patients with an elevated ESWS, the increase in LV mass was due to a larger increase in the LV diameters (LVESD, $32 \pm 6 \mathrm{~mm}$ vs $44 \pm 5 \mathrm{~mm}$, $P<.001)$ and lower RWT $(0.54 \pm 0.10$ vs $0.34 \pm 0.06$, $P<.001)$. Finally, the FTMI was significantly greater in
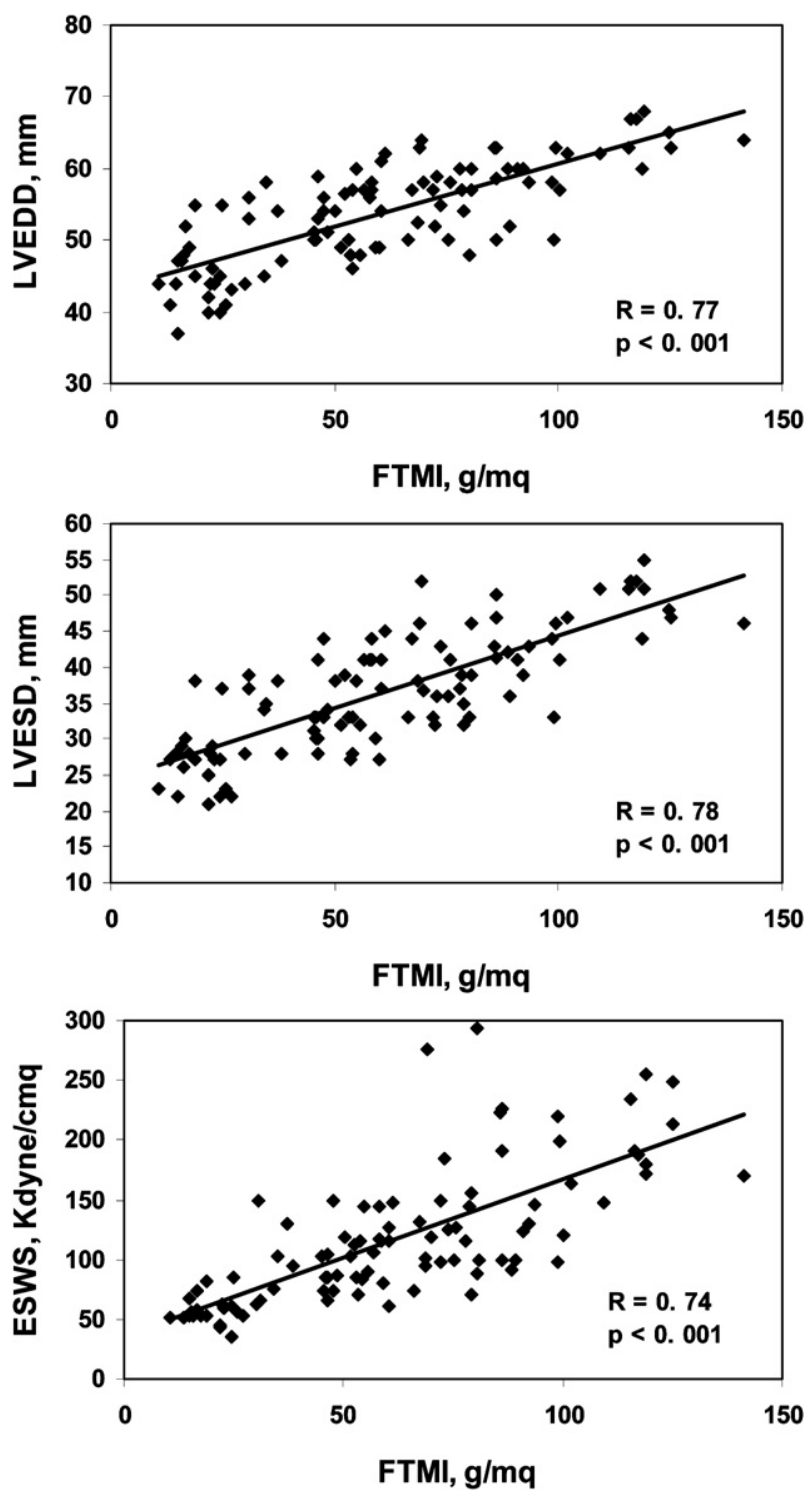

FIGURE 2. Correlation between myocardial fibrosis tissue mass index (FTMI) and baseline echocardiographic characteristics: left ventricular end diastolic diameter (LVEDD), left ventricular end-systolic diameter (LVESD), and end-systolic wall stress (ESWS).

patients with inadequate hypertrophy $\left(88 \pm 27 \mathrm{~g} / \mathrm{m}^{2}\right.$ vs 46 $\left.\pm 23 \mathrm{~g} / \mathrm{m}^{2}, P<.001\right)$.

\section{Clinical Data and Follow-up}

The extent of histologically determined MF correlated closely with the preoperative functional class $(P<.001)$. Hospital mortality was $3 \%$, with 2 deaths from cardiac failure and 1 from acute renal failure; 7 patients experienced cerebrovascular events (7.\%), 14 had low output syndrome $(14 \%)$, and 2 had acute renal failure requiring hemodialysis $(2 \%)$. A total of 96 hospital survivors were followed up for 1 to 12 years, with a mean follow-up of $6.2 \pm 2.9$ years. A total of 32 late deaths occurred due to progressive heart 

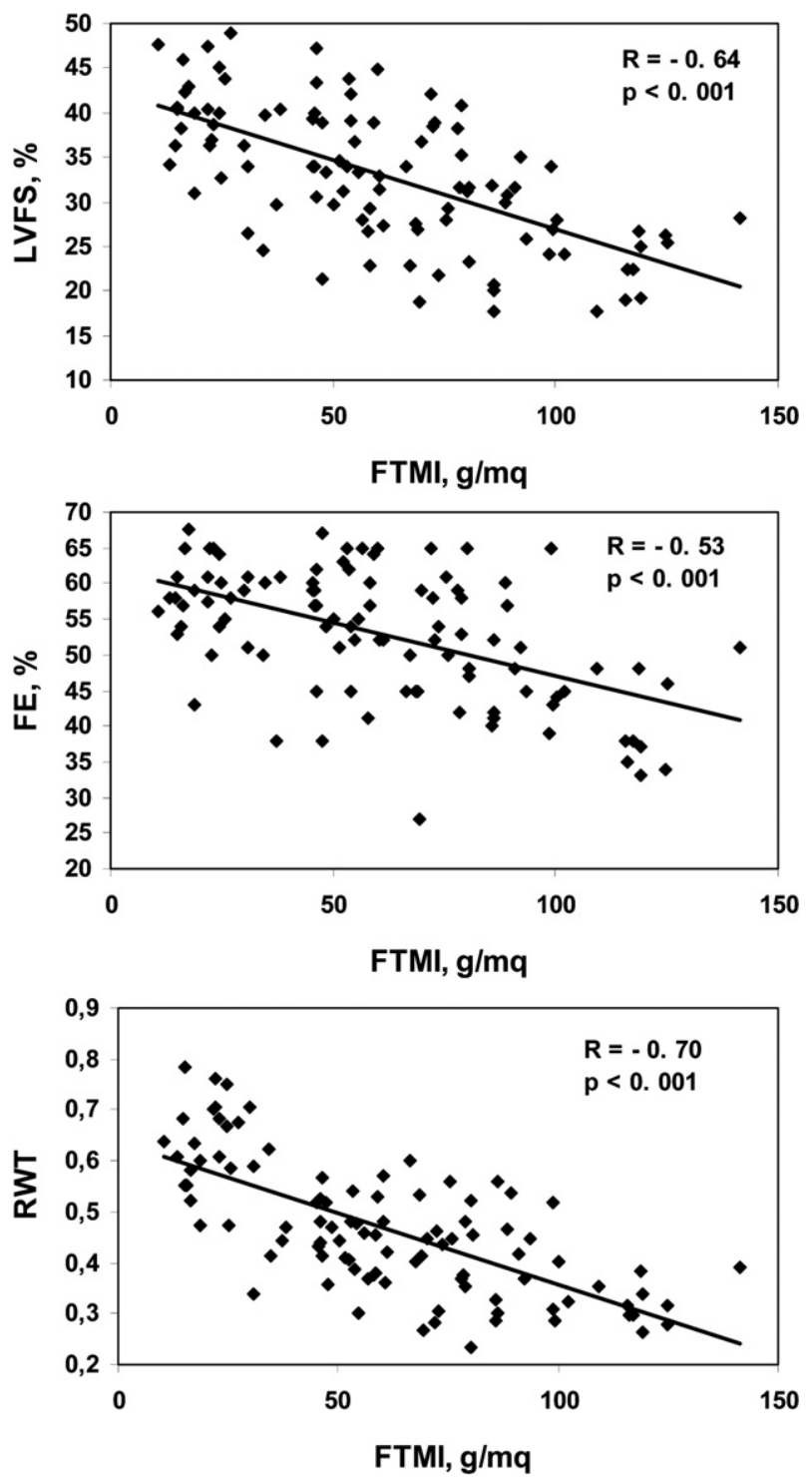

FIGURE 3. Correlation between myocardial fibrosis tissue mass index (FTMI) and baseline left ventricular fractional shortening (LVFS), left ventricular ejection fraction $(L V E F)$, and relative wall thickness $(R W T)$.

failure in 14 patients, stroke in 7 , neoplasia in 6 , myocardial infarction in 3 , senectus in 1 , and sudden cardiac death in 1 . The overall actuarial survival at 10 years was $53 \% \pm 6 \%$. Patients with a higher grade of MF demonstrated significantly lower freedom from cardiac death at 10 years $(42 \% \pm 19 \%$ vs $89 \% \pm 6 \%, P=.002$; Figure 4$)$. In the subgroup of 20 patients who died of a cardiac cause, the preoperative NYHA class, LV dysfunction, and the amount of MF were significantly greater than in those who survived (Table 2). Patient age (hazard ratio [HR], 1.09; $P=.012$ ), preoperative transvalvular gradient less than $40 \mathrm{~mm} \mathrm{Hg}$ (HR, 2.82; $P=.040$ ), preoperative ESWS (HR, 1.01; $P=.046)$, and preoperative FTMI (HR, 1.02; $P=.034$ ) emerged as the strongest independent predictors of cardiac

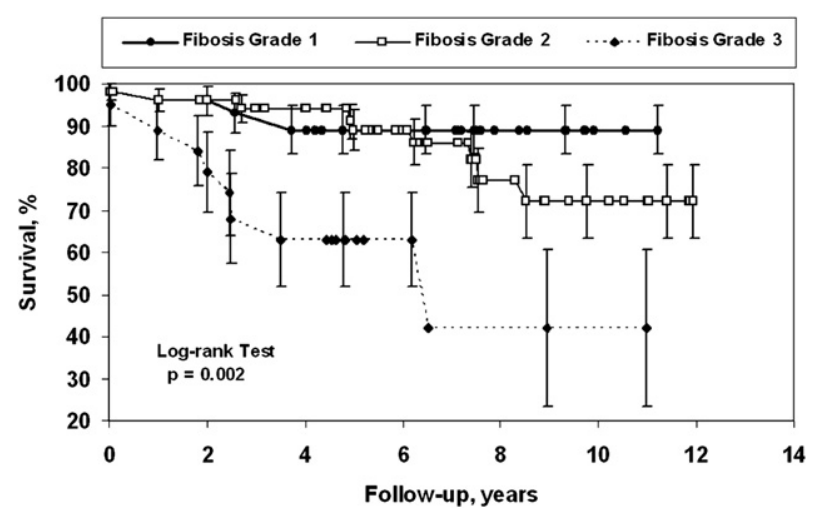

FIGURE 4. Actuarial freedom from cardiac death at 10 years according to myocardial fibrosis grade.

mortality. At the last follow-up visit, the mean NYHA class was $2.3 \pm 0.9$, with 17 patients $(17 \%)$ in functional class I, $46(48 \%)$ in class II, $23(24 \%)$ in class III, and $10(10 \%)$ in class IV. Patients with a mild to moderate grade of fibrosis at baseline showed improvement in the NYHA functional class and LVEF, with a marked reduction of the LV mass index. However, patients with severe fibrosis showed only a slight clinical improvement without any significant changes in LV size, LVFS, and LVEF (Table 3).

\section{DISCUSSION}

Patients with AS have advanced structural alterations of the left ventricle characterized by MF and varying degrees of myocyte degeneration. ${ }^{5,21,22}$ Such changes occur predominantly in the subendocardial layers, leading initially to interstitial fibrosis and followed by complete replacement of the myocardium with fibrous tissue. ${ }^{23}$ The pathophysiologic mechanisms responsible for these alterations include excessive activation of the reninangiotensin system, ${ }^{24,25}$ inhibition of the kallikrein-kinin system, ${ }^{26}$ and increased expression of the tissue inhibitor of metalloproteinase 1 and $2 .^{23,27}$

Improved operative and postoperative management, together with advances in prosthetic technology, have greatly improved the results of AVR for AS. It has been clearly demonstrated that to optimize late patient survival, AVR should also be considered in asymptomatic patients with AS before severe LV hypertrophy develops. The Cleveland Clinic group, in a retrospective observational study of more than 3000 patients undergoing AVR for AS, found that the presence of severe LV hypertrophy, expressed as the LV mass index, was associated with decreased survival being 1 of the major determinants of late death. ${ }^{28}$ The importance of LV mass regression for long-term survival has also been stressed recently by Ali and associates. ${ }^{29}$ They demonstrated that LV mass regression of more than $150 \mathrm{~g}$ was an independent predictor of improved long-term survival on multivariate analysis after AVR at 10 years of 
TABLE 2. Comparative characteristics of surviving patients and those who died of cardiac events

\begin{tabular}{|c|c|c|c|}
\hline Characteristic & $\begin{array}{c}\text { Survivors } \\
(\mathrm{n}=64)\end{array}$ & $\begin{array}{l}\text { Cardiac deaths } \\
\quad(n=20)\end{array}$ & $\begin{array}{c}P \\
\text { value }\end{array}$ \\
\hline Mean age (y) & $69 \pm 10$ & $74 \pm 10$ & .040 \\
\hline Gender & & & .767 \\
\hline Male & 28 & 8 & \\
\hline Female & 36 & 12 & \\
\hline $\mathrm{AF}$ & $10(16)$ & $1(5)$ & .219 \\
\hline Diabetes & $12(19)$ & $5(25)$ & .544 \\
\hline Arterial hypertension & $26(41)$ & $7(35)$ & .653 \\
\hline PVD & $11(17)$ & $4(20)$ & .774 \\
\hline Mean preoperative NYHA & $2.5 \pm 0.7$ & $2.9 \pm 0.6$ & .034 \\
\hline LVEDD (mm) & $53 \pm 7$ & $59 \pm 6$ & .001 \\
\hline LVESD (mm) & $35 \pm 8$ & $43 \pm 6$ & $<.001$ \\
\hline LVPWTd (mm) & $12 \pm 2$ & $11 \pm 2$ & .070 \\
\hline LVPWTs (mm) & $16 \pm 3$ & $15 \pm 3$ & .081 \\
\hline LVSWTd (mm) & $14 \pm 2$ & $13 \pm 2$ & .045 \\
\hline LVSWTs (mm) & $18 \pm 3$ & $16 \pm 3$ & .052 \\
\hline LVFS (\%) & $34 \pm 8$ & $27 \pm 5$ & $<.001$ \\
\hline RWT & $0.48 \pm 0.13$ & $0.39 \pm 0.11$ & .007 \\
\hline LVEF (\%) & $55 \pm 8$ & $46 \pm 10$ & $<.001$ \\
\hline $\mathrm{LVEF}<50 \%$ & $12(19)$ & $14(70)$ & $<.001$ \\
\hline $\operatorname{LVMI}\left(\mathrm{g} / \mathrm{m}^{2}\right)$ & $191 \pm 31$ & $202 \pm 38$ & .172 \\
\hline ESWS (kdyne/cm²) & $105 \pm 50$ & $165 \pm 65$ & $<.001$ \\
\hline Aortic PG (mm Hg) & $79 \pm 18$ & $72 \pm 19$ & .138 \\
\hline Aortic MG (mm Hg) & $50 \pm 12$ & $44 \pm 13$ & .063 \\
\hline Aortic MG $<40 \mathrm{~mm} \mathrm{Hg}$ & $11(17)$ & $10(50)$ & .003 \\
\hline Aortic VAi $\left(\mathrm{cm}^{2} / \mathrm{m}^{2}\right)$ & $0.39 \pm 0.10$ & $0.41 \pm 0.10$ & .375 \\
\hline Fibrosis grade I & $22(34)$ & $3(15)$ & .098 \\
\hline Fibrosis grade II & $31(48)$ & $9(45)$ & .788 \\
\hline Fibrosis grade III & $11(17)$ & $8(40)$ & .033 \\
\hline FTMI $\left(\mathrm{g} / \mathrm{m}^{2}\right)$ & $53 \pm 30$ & $89 \pm 32$ & $<.001$ \\
\hline MTMI $\left(\mathrm{g} / \mathrm{m}^{2}\right)$ & $77 \pm 35$ & $85 \pm 34$ & .328 \\
\hline
\end{tabular}

Data presented as mean \pm standard deviation or numbers, with percentages in parentheses. $M F$, Myocardial fibrosis; $A F$, atrial fibrillation; $P V D$, peripheral vascular disease; NYHA, New York Heart Association functional class; $L V E D D$, left ventricular end diastolic diameter; LVESD, left ventricular end-systolic diameter; LVPWTd, left ventricular diastolic posterior wall thickness; $L V P W T$, left ventricular systolic posterior wall thickness; $L V S W T d$, left ventricular diastolic septal thickness; LVSWTs, left ventricular systolic septal thickness; $L V F S$, left ventricular fractional shortening; $R W T$, relative wall thickness; $L V E F$, left ventricular ejection fraction; $L V M I$, left ventricular mass index; ESWS, end systolic wall stress; RVSP, right ventricular systolic pressure; $R V D P$, right ventricular diastolic pressure; $P A S P$, pulmonary artery systolic pressure; $P A D P$, pulmonary artery diastolic pressure; $M W P$, mean wedge pressure; $P G$, peak gradient; $M G$, mean gradient; $V A i$, indexed valve area; $F T M I$, fibrosis tissue mass index; MTMI, myocyte tissue mass index.

follow-up. ${ }^{29}$ The role of fibrotic changes in the hypertrophied myocardium of patients with severe AS in influencing the late results of AVR has been not thoroughly investigated. We believe that information on this issue should be of great value for the cardiac surgical community to help define better indications and timing for patients scheduled for AVR for AS.

In our study, it was possible to confirm varying degrees of interstitial MF in all patients with AS, as demonstrated by Hein and colleagues ${ }^{5}$; such changes were significantly greater in the patients with severe LV dysfunction. This inverse relationship between MF and LV function has been previously reported. ${ }^{26}$ However, few studies have investigated the relationship between the amount of MF and LV functional recovery after AVR. ${ }^{5,9,19,21,30}$ Hein and colleagues ${ }^{5}$ showed that a high degree of MF was the major determinant of the persistence of severe myocardial dysfunction, even after AVR. However, according to Krayenbuehl and associates, ${ }^{21}$ only the presence of a reduced LVEF before AVR, but not the extent of MF, was a predictor of persistent LV dysfunction postoperatively. However, the LVEF is determined mainly by the radial myocardial function, which is not substantially affected by the subendocardial abnormalities typical of interstitial fibrosis. ${ }^{31}$ It was previously shown that the LVEF is reduced only in the late stage of valvular disease when the radial and longitudinal function has decreased. ${ }^{30}$ We found a strong correlation between the degree of MF and LVEDD, LVESD, and LVFS.

To better assess the LV impairment induced by valve stenosis, we evaluated the ESWS, which showed a good correlation with the degree of MF. MF was increased in patients with inadequate LV hypertrophy compared with those with adequate hypertrophy. Moreover, in patients with adequate hypertrophy and normalized wall stress, the increased LV mass was related to the increment in wall thickness, rather than to the LV diameters. In contrast, in patients with elevated stress, the increment in LV mass was secondary to a greater increase in the LV diameters, with lower LV wall thickness.

A limitation of the present study was that it was a retrospective evaluation of a series of patients undergoing AVR during a period when the modern noninvasive techniques for MF evaluation were not yet available. We realize that the calculation of ESWS is an obsolete technique for the evaluation of MF; however, it has been useful in identifying a subgroup of patients at highest risk. In recent years, contrast-enhanced magnetic resonance imaging has been shown to provide an accurate assessment of myocardial necrosis and MF, not only in the setting of myocardial infarction, ${ }^{32,33}$ but also in a variety of other cardiomyopathies. ${ }^{34-36}$ Azevedo and colleagues ${ }^{10}$ have shown that in patients with severe aortic valve disease, the amount of MF, determined by either histologic examination or contrast-enhanced magnetic resonance imaging, is associated with the degree of LV functional improvement after surgery. They also observed that greater degrees of MF were associated with worse long-term survival after AVR. Finally, the same study found patient age and the amount of MF to be independent predictors of mortality for all causes. Our study demonstrated that the FTMI in the subgroup of patients who died of cardiac events was greater than in those who were alive at late follow-up $(89 \pm 32$ vs $53 \pm 30, P<.001)$. Similarly, 10 years after AVR, patients with a preoperatively greater amount of MF had a lower freedom from cardiac death compared with the patients with a lower MF grade $(42 \% \pm 19 \%$ vs $89 \% \pm 6 \%$, 
TABLE 3. Hemodynamic profile according to myocardial fibrosis grade

\begin{tabular}{|c|c|c|c|c|c|c|}
\hline \multirow[b]{2}{*}{ Variable } & \multicolumn{2}{|c|}{ Fibrosis grade I } & \multicolumn{2}{|c|}{ Fibrosis grade II } & \multicolumn{2}{|c|}{ Fibrosis grade III } \\
\hline & $\begin{array}{l}\text { Preoperative } \\
(\mathbf{n}=\mathbf{2 8})\end{array}$ & $\begin{array}{l}\text { Postoperative } \\
(\mathbf{n}=\mathbf{2 8})\end{array}$ & $\begin{array}{l}\text { Preoperative } \\
\quad(\mathbf{n}=\mathbf{5 2})\end{array}$ & $\begin{array}{l}\text { Postoperative } \\
\quad(\mathbf{n}=\mathbf{5 0})\end{array}$ & $\begin{array}{l}\text { Preoperative } \\
(\mathbf{n}=19)\end{array}$ & $\begin{array}{c}\text { Postoperative } \\
(\mathbf{n}=18)\end{array}$ \\
\hline Mean NYHA & $2.4 \pm 0.7$ & $1.9 \pm 0.6^{*}$ & $2.5 \pm 0.7$ & $2.2 \pm 0.8^{*}$ & $3.1 \pm 0.6$ & $3.2 \pm 0.8$ \\
\hline $\operatorname{LVEDD}(\mathrm{mm})$ & $47 \pm 6$ & $46 \pm 6^{*}$ & $54 \pm 5$ & $53 \pm 5^{*}$ & $63 \pm 4$ & $63 \pm 4$ \\
\hline LVESD (mm) & $29 \pm 6$ & $30 \pm 5 \dagger$ & $37 \pm 5$ & $36 \pm 6$ & $47 \pm 5$ & $48 \pm 5$ \\
\hline LVFS (\%) & $39 \pm 6$ & $41 \pm 6$ & $33 \pm 6$ & $34 \pm 7$ & $24 \pm 6$ & $24 \pm 5$ \\
\hline RWT & $0.61 \pm 0.10$ & $0.49 \pm 0.07 \dagger$ & $0.44 \pm 0.07$ & $0.37 \pm 0.07 \dagger$ & $0.31 \pm 0.04$ & $0.37 \pm 0.12^{*}$ \\
\hline LVEF (\%) & $57 \pm 7$ & $60 \pm 10^{*}$ & $55 \pm 8$ & $57 \pm 8$ & $42 \pm 7$ & $40 \pm 5$ \\
\hline LVMI (g/m²) & $196 \pm 33$ & $118 \pm 30 \dagger$ & $194 \pm 30$ & $134 \pm 37 \dagger$ & $190 \pm 38$ & $173 \pm 36 \dagger$ \\
\hline $\begin{array}{l}\text { Aortic MG } \\
\qquad(\mathrm{mm} \mathrm{Hg})\end{array}$ & $50 \pm 11$ & $13 \pm 4 \dagger$ & $51 \pm 14$ & $12 \pm 3 \dagger$ & $44 \pm 12$ & $12 \pm 3 \dagger$ \\
\hline Aortic VAi $\left(\mathrm{cm}^{2} / \mathrm{m}^{2}\right)$ & $0.39 \pm 0.08$ & $0.93 \pm 0.19 \dagger$ & $0.38 \pm 0.09$ & $0.99 \pm 0.19 \dagger$ & $0.40 \pm 0.10$ & $0.93 \pm 0.12 \dagger$ \\
\hline ESWS (kdyne/ $\mathrm{cm}^{2}$ ) & $65 \pm 20$ & $68 \pm 18$ & $109 \pm 30$ & $114 \pm 33$ & $206 \pm 41$ & $182 \pm 36 \dagger$ \\
\hline
\end{tabular}

NYHA, New York Heart Association functional class; $L V E D D$, left ventricular end-diastolic diameter; $L V E S D$, left ventricular end-systolic diameter; $L V F S$, left ventricular fractional shortening; $R W T$, relative wall thickness; $L V E F$, left ventricular ejection fraction; $L V M I$, left ventricular mass index; $M G$, mean gradient; $V A i$, indexed valve area; $E S W S$, end-systolic wall stress. ${ }^{*} P<.05 ; \dagger P<.001$ (both values for within-group comparison).

$P=.002)$. Moreover, multivariate analysis showed that an increased ESWS and the degree of MF were incremental risk factors for mortality from cardiac causes.

The clinical treatment of patients with AS is determined by the symptoms and echocardiographic parameters such as LVEF, transvalvular gradients, and aortic valve area. However, these parameters are dependent on the stroke volume, are not always symptom related, and do not predict the clinical outcome after AVR. ${ }^{8}$ Our results have indicated that the quantitative assessment of MF has the potential to provide additional prognostic information in the evaluation of patients with severe AS, particularly in those with a low gradient and LV dysfunction. In our study, the degree of MF was assessed by ultrastructural evaluation of biopsy fragments obtained only from the interventricular septum and not from the entire LV wall. This, despite the relevance of the technique, remains another potential limitation of the study. Newer techniques especially designed for the assessment of diffuse $\mathrm{MF}$, such as myocardium $\mathrm{T}_{1}$-weighted mapping and contrast-enhanced magnetic resonance imaging, are now available. ${ }^{8,35-38}$ However, until these sophisticated techniques are readily available, noninvasive techniques such as the echocardiographic assessment of mitral annulus displacement can be useful in identifying patients with LV dysfunction related to MF. ${ }^{39}$ Weidemann and colleagues, ${ }^{9}$ in evaluating patients with severe AS, have shown that displacement of the mitral annulus greater than $7 \mathrm{~mm}$ proved to be an excellent positive predictor for LV functional improvement after AVR. More recently, the same group, studying patients with severe AS and a low gradient, showed a close inverse correlation between interstitial fibrosis and mitral ring displacement. ${ }^{11}$ The assessment of mitral ring displacement was also shown to be useful in differentiating moderate AS with a low gradient from severe AS with a preserved ejection fraction. ${ }^{11}$
In conclusion, the results of the present study indicate that in patients with severe $\mathrm{AS}$, a reduced $\mathrm{LV}$ function and increased LV diameters are strongly related to the amount of MF, which significantly affects long-term survival after AVR. Future research should be directed toward developing strategies to allow the earlier detection of MF to improve the long-term outcomes after AVR for AS.

\section{References}

1. Carabello BA, Paulus WJ. Aortic stenosis. Lancet. 2009;373:956-66.

2. Grossman W, Jones D, McLaurin LP. Wall stress and patterns of hypertrophy in the human left ventricle. J Clin Invest. 1975;56:56-64.

3. Chambers J. The left ventricle in aortic stenosis: evidence for the use of ACE inhibitors. Heart. 2006;92:420-3.

4. Kupari M, Turto H, Lommi J. Left ventricular hypertrophy in aortic valve stenosis: preventive or promotive of systolic dysfunction and heart failure? Eur Heart J. 2005;26:1790-6.

5. Hein S, Arnon E, Kostin S, Schonburg M, Elsasser A, Polyakova V, et al. Progression from compensated hypertrophy to failure in the pressure-overloaded human heart: structural deterioration and compensatory mechanisms. Circulation. 2003; 107:984-91.

6. Weber KT. From inflammation to fibrosis: a stiff stretch of highway. Hypertension. 2004;43:716-9.

7. Serneri GG, Modesti PA, Boddi M, Cecioni I, Paniccia R, Coppo M, et al. Cardiac growth factors in human hypertrophy: relations with myocardial contractility and wall stress. Circ Res. 1999;85:57-67.

8. Hachicha Z, Dumesnil JG, Bogaty P, Pibarot P. Paradoxical low-flow, low-gradient severe aortic stenosis despite preserved ejection fraction is associated with higher afterload and reduced survival. Circulation. 2007;115:2856-64.

9. Weidemann F, Herrmann S, Stork S, Niemann M, Frantz S, Lange V, et al. Impact of myocardial fibrosis in patients with symptomatic severe aortic stenosis. Circulation. 2009; $120: 577-84$

10. Azevedo CF, Nigri M, Higuchi ML, Pomerantzeff PM, Spina GS, Sampaio RO, et al. Prognostic significance of myocardial fibrosis quantification by histopathology and magnetic resonance imaging in patients with severe aortic valve disease. J Am Coll Cardiol. 2010;56:278-87.

11. Herrmann S, Stork S, Niemann M, Lange V, Strotmann JM, Frantz S, et al. Lowgradient aortic valve stenosis myocardial fibrosis and its influence on function and outcome. J Am Coll Cardiol. 2011;58:402-12.

12. Baumgartner H, Hung J, Bermejo J, Chambers JB, Evangelista A, Griffin BP, et al. Echocardiographic assessment of valve stenosis: EAE/ASE recommendations for clinical practice. Eur J Echocard. 2009;10:1-25. 
13. Devereux RB, Reichek N. Echocardiographic determination of left ventricular mass in man: anatomic validation of the method. Circulation. 1977;55: 613-8.

14. Reichek N, Wilson J, St John SM, Plappert TA, Goldberg S, Hirshfeld JW. Noninvasive determination of left ventricular end-systolic stress: validation of the method and initial application. Circulation. 1982;65:99-108.

15. Baandrup U, Florio RA, Rehahn M, Richardson PJ, Olsen EG. Critical analysis of endomyocardial biopsies from patients suspected of having cardiomyopathy. II: comparison of histology and clinical/haemodynamic information. Br Heart $\mathrm{J}$. 1981;45:487-93.

16. Lund $O$. Preoperative risk evaluation and stratification of long-term survival after valve replacement for aortic stenosis: reasons for earlier operative intervention. Circulation. 1990;82:124-39.

17. Tanaka M, Fujiwara H, Onodera T, Wu DJ, Hamashima Y, Kawai C. Quantitative analysis of myocardial fibrosis in normals, hypertensive hearts, and hypertrophic cardiomyopathy. Br Heart J. 1986;55:575-81.

18. Baandrup U, Florio RA, Olsen EG. Do endomyocardial biopsies represent the morphology of the rest of the myocardium? A quantitative light microscopic study of single vs multiple biopsies with the King's bioptome. Eur Heart J. 1982;3:171-8.

19. Lund O, Kristensen LH, Baandrup U, Hansen OK, Nielsen TT, Emmertsen K, et al. Myocardial structure as a determinant of pre- and postoperative ventricular function and long-term prognosis after valve replacement for aortic stenosis. Eur Heart J. 1998;19:1099-108

20. Akins CW, Miller DC, Turina MI, Kouchoukos NT, Blackstone EH, Grunkemeier GL, et al. Guidelines for reporting mortality and morbidity after cardiac valve interventions. J Thorac Cardiovasc Surg. 2008;135:732-8

21. Krayenbuehl HP, Hess OM, Monrad ES, Schneider J, Mall G, Turina M. Left ventricular myocardial structure in aortic valve disease before, intermediate, and late after aortic valve replacement. Circulation. 1989;79:744-55.

22. Maron BJ, Ferrans VJ, Roberts WC. Myocardial ultrastructure in patients with chronic aortic valve disease. Am J Cardiol. 1975;35:725-39.

23. Heymans S, Schroen B, Vermeersch P, Milting H, Gao F, Kassner A, et al. Increased cardiac expression of tissue inhibitor of metalloproteinase-1 and tissue inhibitor of metalloproteinase- 2 is related to cardiac fibrosis and dysfunction in the chronic pressure-overloaded human heart. Circulation. 2005; 112:1136-44.

24. Fielitz J, Hein S, Mitrovic V, Pregla R, Zurbrugg HR, Warnecke C, et al. Activation of the cardiac renin-angiotensin system and increased myocardial collagen expression in human aortic valve disease. J Am Coll Cardiol. 2001;37:1443-9.

25. Walther T, Schubert A, Falk V, Binner C, Walther C, Doll N, et al. Left ventricular reverse remodeling after surgical therapy for aortic stenosis: correlation to reninangiotensin system gene expression. Circulation. 2002;106:I23-6.
26. Helske S, Laine M, Kupari M, Lommi J, Turto H, Nurmi L, et al. Increased expression of profibrotic neutral endopeptidase and bradykinin type 1 receptors in stenotic aortic valves. Eur Heart J. 2007;28:1894-903.

27. Kitaoka H, Kubo T, Okawa M, Hayato K, Yamasaki N, Matsumura Y, et al. Impact of metalloproteinases on left ventricular remodeling and heart failure events in patients with hypertrophic cardiomyopathy. Circ J. 2010;74:1191-6.

28. Mihaljevic T, Nowicki ER, Rajeswaran J, Blackstone EH, Lagazzi L, Thomas J, et al. Survival after valve replacement for aortic stenosis: implication for decision making. J Thorac Cardiovasc Surg. 2008;135:1270-9.

29. Ali A, Patel A, Ali Z, Abu-Omar Y, Saeed A, Athanasiou T, et al. Enhanced left ventricular mass regression after aortic valve replacement in patients with aortic stenosis is associated with improved long-term survival. $J$ Thorac Cardiovasc Surg. 2011;142:285-91.

30. Hess OM, Ritter M, Schneider J, Grimm J, Turina M, Krayenbuehl HP. Diastolic stiffness and myocardial structure in aortic valve disease before and after valve replacement. Circulation. 1984;69:855-65.

31. MacIver DH, Townsend M. A novel mechanism of heart failure with normal ejection fraction. Heart. 2008;94:446-9.

32. Kim RJ, Wu E, Rafael A, Chen EL, Parker MA, Simonetti O, et al. The use of contrast-enhanced magnetic resonance imaging to identify reversible myocardial dysfunction. $N$ Engl J Med. 2000;343:1445-53.

33. Wagner A, Mahrholdt H, Holly TA, Elliott MD, Regenfus M, Parker M, et al. Contrast-enhanced MRI and routine single photon emission computed tomography (SPECT) perfusion imaging for detection of subendocardial myocardial in farcts: an imaging study. Lancet. 2003;361:374-9.

34. Flett AS, Hayward MP, Ashworth MT, Hansen MS, Taylor AM, Elliott PM, et al Equilibrium contrast cardiovascular magnetic resonance for the measurement of diffuse myocardial fibrosis: preliminary validation in humans. Circulation. 2010; $122: 138-44$

35. Kramer CM. Cardiac magnetic resonance imaging identification of myocardia fibrosis: the need for standardization and therapies. J Am Coll Cardiol. 2010 $56: 288-9$

36. Mewton N, Liu CY, Croisille P, Bluemke D, Lima JAC. Assessment of myocardial fibrosis with cardiovascular magnetic resonance. J Am Coll Cardiol. 2011 57:891-903

37. Iles L, Pfluger H, Phrommintikul A, Cherayath J, Aksit P, Gupta SN, et al. Evaluation of diffuse myocardial fibrosis in heart failure with cardiac magnetic resonance contrast-enhanced T1 mapping. J Am Coll Cardiol. 2008;52:1574-80.

38. Moon JC, Reed E, Sheppard MN, Elkington AG, Ho SY, Burke M, et al. The histologic basis of late gadolinium enhancement cardiovascular magnetic resonance in hypertrophic cardiomyopathy. J Am Coll Cardiol. 2004;43:2260-4.

39. Leong DP, Madsen PL, Selvanayagam JB. Non-invasive evaluation of myocardial fibrosis: implications for the clinician. Heart. 2010;96:2016-24. 